Cite this: Chem. Commun., 2012, 48, 2207-2209

\section{Polyoxometalate-directed assembly of water-soluble AgCl nanocubes $\dagger$}

\author{
Alevtina Neyman, ${ }^{a}$ Yifeng Wang, ${ }^{a}$ Shelly Sharet, ${ }^{a}$ Neta Varsano, ${ }^{a}$ Bogdan Botar, ${ }^{b}$ \\ Paul Kögerler, ${ }^{b c}$ Louisa Meshi $^{d e}$ and Ira A. Weinstock $* a e$
}

Received 11th October 2011, Accepted 16th December 2011

DOI: $10.1039 / \mathrm{c} 2 \mathrm{cc} 16322 \mathrm{e}$

"Out-of-pocket" association of $\mathrm{Ag}^{+}$to the tetradentate defect site of mono-vacant Keggin and Wells-Dawson polyoxometalate (POM) cluster-anions is used to direct the formation of watersoluble AgCl nanocubes.

Silver halide ${ }^{1 a}$ and carbonate $^{1 b}$ nanoparticles are potent antimicrobial agents, while silver halides - indirect band-gap materials ${ }^{2}$ - are active components of UV- and visible-light photocatalysts for pollutant degradation, ${ }^{3 a} \mathrm{H}_{2}$ evolution, ${ }^{3 b}$ and water oxidation. ${ }^{3 c, d}$ Meanwhile, POMs have been used as functional protecting ligands for metal( 0 ) nanoparticles, ${ }^{4}$ and for "decorating" preformed titania ${ }^{5}$ and alumina-coated silica nanoparticles. ${ }^{6}$ We now show that "out-of-pocket" association between $\mathrm{Ag}^{+}$and the defect sites of mono-vacant Keggin and Wells-Dawson ions can be used to control the formation of $\mathrm{POM}$-protected $\mathrm{AgCl}$ nanocrystals in water, the first POM-directed synthesis of a binary-element nanocrystal.

Mono-vacant derivatives of plenary Keggin and Wells-Dawson ions are polydentate ligands for main-group, transition metal, lanthanide and actinide cations. ${ }^{7}$ The defect, or mono-vacant, anions are prepared by formally removing a single $\mathrm{W}=\mathrm{O}^{4+}$ moiety from the plenary Keggin (eqn (1)) or Wells-Dawson ions, $\left[\mathrm{X}^{n+} \mathrm{W}_{12} \mathrm{O}_{40}\right]^{(n-8)-}$ or $\left[\mathrm{X}_{2}{ }^{n+} \mathrm{W}_{18} \mathrm{O}_{62}\right]^{(2 n-16)-}$, respectively $\left(\mathrm{X}^{n+}\right.$ is typically a main-group cation).

$$
\left[\mathrm{X}^{n+} \mathrm{W}_{12} \mathrm{O}_{40}\right]^{(n-8)-} \stackrel{-“ \mathrm{~W}=\mathrm{O}^{4+} ”}{\longrightarrow}\left[\mathrm{X}^{n+} \mathrm{W}_{11} \mathrm{O}_{39}\right]^{(n-12)-}
$$

When these molecular anions serve as ligands, smaller metal cations reside inside the defect site, while larger ones bind in an "out-of-pocket" fashion slightly above the plane defined by the $4 \mathrm{~W}-\mathrm{O}^{-}$ligands around the vacancy. ${ }^{8}$

The sequential addition of $\mathrm{AgNO}_{3}$ and $\mathrm{KCl}(10 \mu \mathrm{mol}$ of each) to a vigorously stirred solution of the $\mathrm{K}^{+}$salt of the

${ }^{a}$ Ben Gurion University of the Negev, Dept. of Chem., Beer Sheva, Israel.E-mail:iraw@bgu.ac.il

${ }^{b}$ Peter Grünberg Institute-6, Research Centre Jülich, Jülich, Germany ${ }^{c}$ RWTH Aachen University, Institute of Inorg. Chem., Aachen, Germany

${ }^{d}$ Ben Gurion University of the Negev, Dept. of Mater. Eng.,

Beer Sheva, Israel

${ }^{e}$ Ben Gurion University of the Negev, Ilse Katz Institute for

Nanoscale Science \& Technology, Beer Sheva, Israel

$\dagger$ Electronic supplementary information (ESI) available: Syntheses, electron microscopic, dynamic light-scattering and spectroscopic data, calculations, and crystallographic data. CCDC 838469. For ESI and crystallographic data in CIF or other electronic format see DOI: $10.1039 / \mathrm{c} 2 \mathrm{cc} 16322 \mathrm{e}$


Fig. 1 Self-assembly and stabilization of $\mathrm{AgCl}$ by mono-vacant $\left[\alpha-\mathrm{PW}_{11} \mathrm{O}_{39}\right]^{7-}(\mathbf{1})$ in water. (Left) $\mathbf{1}$ in polyhedral notation: $\mathrm{W}(\mathrm{vI})$ atoms are at the centers of the green polyhedra, oxygen atoms lie at their vertices, the heteroatom, $\mathrm{X}^{n+}=\mathrm{P}^{5+}$, resides in a local $T_{\mathrm{d}}$ site (red) at the center, and the defect site is at the lower right of the structure. (Right) the resultant solution, $2.0 \mathrm{mM}$ in each component: $1, \mathrm{Ag}^{+}$and $\mathrm{Cl}^{-}$.

mono-vacant anion $\left[\alpha-\mathrm{PW}_{11} \mathrm{O}_{39}\right]^{7-}(\mathbf{1} ; 10 \mu \mathrm{mol})$ in $5 \mathrm{~mL}$ of water at $22{ }^{\circ} \mathrm{C}$ results in a clear solution (Fig. 1).

Although the product of the concentrations of $\mathrm{Ag}^{+}$and $\mathrm{Cl}^{-}$ $\left(4 \times 10^{-6} \mathrm{M}^{2}\right)$ is $c a .22000$ times larger than the $K_{\mathrm{sp}}$ of $\mathrm{AgCl}(\mathrm{s})$ $\left(1.8 \times 10^{-10} \mathrm{M}^{2}\right)$, no precipitate is observed.

When the clear solution shown in Fig. 1 was dried for transmission electron microscopy (TEM), the images revealed aggregates of polycrystalline $\mathrm{AgCl}(\mathrm{s})$ embedded in amorphous $\mathrm{K}_{7}\left[\alpha-\mathrm{PW}_{11} \mathrm{O}_{39}\right]$ (see ESI $\dagger$ ). Suspecting that the nanostructures were disrupted upon drying, ${ }^{9}$ TEM images were obtained after cryogenic "trapping" in a vitreous-water matrix (Fig. 2A). Abundant cubic objects were observed, with median edge lengths of $29 \pm 4 \mathrm{~nm}$ (panel B). Dynamic light scattering (DLS, inset to panel B) indicated an average hydrodynamic radius $\left(R_{\mathrm{h}}\right)$ of $20 \mathrm{~nm}$, and a narrow $R_{\mathrm{h}}$ distribution of 17-24 nm (Fig. 2B, inset).
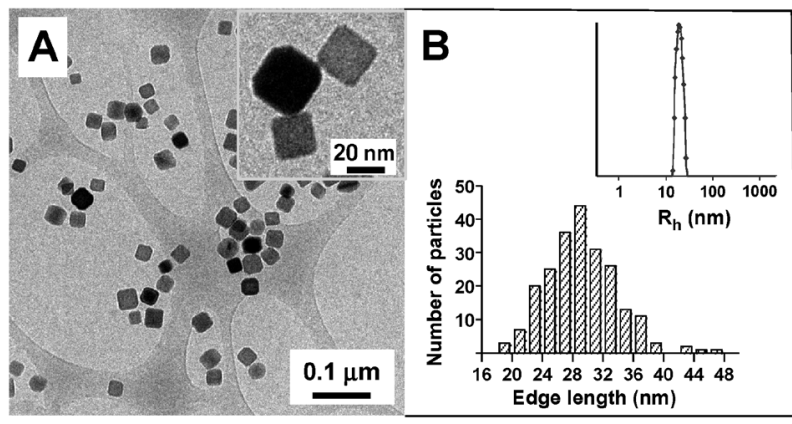

Fig. 2 (A) Cryo-TEM images of $\mathbf{1}$-stablized $\mathrm{AgCl}$ nanocubes. Variations in particle color/darkness result from small variations in thickness, and from the nanocubes lying at different Bragg conditions, leading to differences in diffraction contrast. (B) A histogram of particle-edge lengths from cryo-TEM images; median edge length $=29 \pm 4 \mathrm{~nm}$ (mean deviation). Inset to panel B: DLS measurement of $R_{\mathrm{h}}$. 
In addition, electron crystallography under cryogenic conditions confirmed that the nanocubes possessed crystalline $\mathrm{AgCl}$ "cores" (see ESI $\dagger$ ).

When the reaction shown in Fig. 1 was carried out using the plenary $\left[\alpha-\mathrm{PW}_{12} \mathrm{O}_{40}\right]^{3-}$ ion, which has a smaller negative charge than $\mathbf{1}$, and no defect (lacunary) site for binding to $\mathrm{Ag}^{+}$, much cloudiness was observed. DLS revealed much larger particles, with an average $R_{\mathrm{h}}$ of $c a .95 \mathrm{~nm}$, and a broad distribution of $77-120 \mathrm{~nm}$.

The effects of POM structure and charge were systematically evaluated using a series of plenary and mono-defect cluster-anions. For this, specific heteroatoms, $\mathrm{X}^{n+}$, were used to incrementally vary the negative charges of iso-structural Keggin anions, $\left[\alpha-\mathrm{X}^{n+} \mathrm{W}_{12} \mathrm{O}_{40}\right]^{(8-n)-}$, from 3- to 6-, and of mono-vacant anions, $\left[\alpha-\mathrm{X}^{n+} \mathrm{W}_{11} \mathrm{O}_{39}\right]^{(12-n)-}$ from $7-$ to $9-$. A mono-vacant Wells-Dawson ion, $\left[\alpha_{2}-\mathrm{P}_{2} \mathrm{~W}_{17} \mathrm{O}_{61}\right]^{10-}$, was also included. These were reacted sequentially with $\mathrm{Ag}^{+}$and $\mathrm{Cl}^{-}$(1 equivalent of each) as described above. Particle sizes (average $R_{\mathrm{h}}$ values from DLS data), and size distributions, are listed in Table 1 and the $R_{\mathrm{h}}$ values are plotted as a function of anion charge in Fig. 3.

For the plenary (dodecatungstate) Keggin anions (charges of 3- through 6-), considerable cloudiness was observed, and DLS data revealed particles with hydrodynamic radii of 75-95 nm and broad size distributions. For the mono-defect structures (charges of 7- through 10-), little or no cloudiness was observed and DLS data revealed consistently smaller particles $\left(R_{\mathrm{h}}=18-22 \mathrm{~nm}\right)$ and narrow size distributions. The observation

Table 1 Ligand effectiveness by Dynamic Light Scattering (DLS)

\begin{tabular}{lllrl}
\hline Entry & $\begin{array}{l}\text { Heteropolyanion } \\
\text { salt }\end{array}$ & $\begin{array}{l}\text { Anion } \\
\text { charge }\end{array}$ & $\begin{array}{l}R_{\mathrm{h}} / \\
\mathrm{nm}\end{array}$ & $\begin{array}{l}\text { Size distribution/ } \\
\mathrm{nm}\end{array}$ \\
\hline 1 & None (control) & - & 248 & $138-555^{a}$ \\
2 & $\mathrm{H}_{3}\left[\alpha-\mathrm{PW}_{12} \mathrm{O}_{40}\right]$ & $3-$ & 95 & $77-120$ \\
3 & $\mathrm{H}_{4}\left[\alpha-\mathrm{SiW}_{12} \mathrm{O}_{40}\right]$ & $4-$ & 75 & $49-120$ \\
4 & $\mathrm{~K}_{5}\left[\alpha-\mathrm{AlW}_{12} \mathrm{O}_{40}\right]$ & $5-$ & 88 & $47-159$ \\
5 & $\mathrm{Na}_{6}\left[\alpha-\mathrm{H}_{2} \mathrm{~W}_{12} \mathrm{O}_{40}\right]$ & $6-$ & 92 & $47-151$ \\
6 & $\mathrm{~K}_{7}\left[\alpha-\mathrm{PW}_{11} \mathrm{O}_{39}\right]\left(\mathrm{K}_{7} \mathbf{1}\right)$ & $7-$ & 20 & $17-24$ \\
7 & $\mathrm{~K}_{8}\left[\alpha-\mathrm{SiW}_{11} \mathrm{O}_{39}\right]$ & $8-$ & 18 & $16-21$ \\
8 & $\mathrm{Na}_{9}\left[\alpha-\mathrm{AlW}_{11} \mathrm{O}_{39}\right]$ & $9-$ & 22 & $15-30$ \\
9 & $\mathrm{~K}_{10}\left[\alpha_{2}-\mathrm{P}_{2} \mathrm{~W}_{17} \mathrm{O}_{61}\right]$ & $10-$ & 18 & $16-20$
\end{tabular}

${ }^{a}$ No heteropolyanion present: after allowing $\mathrm{AgCl}(\mathrm{s})$ to settle, an aliquot of clear supernatant was diluted $\sim 20$ folds prior to DLS.

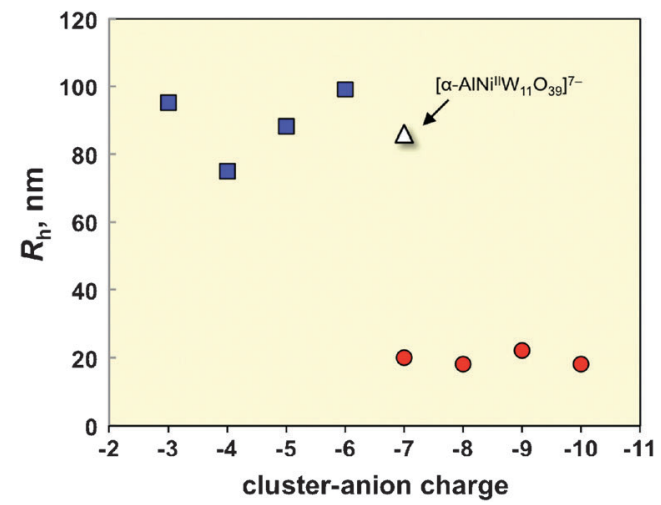

Fig. $3 R_{\mathrm{h}}$ values of $\mathrm{AgCl}$ solutions prepared using plenary Keggin anions (no vacant sites; blue squares), and mono-vacant ions (red circles). The open triangle (for $\left[\alpha-\mathrm{AlNi}^{\mathrm{II}} \mathrm{W}_{11} \mathrm{O}_{39}\right]^{7-}$ ) is described in the text. of these two distinct size domains (Fig. 3) was the first line of quantitative evidence that the binding site in the mono-defect anions played an important role in the growth and stabilization of the $\mathrm{AgCl}$ nanocrystals.

However, the defect structures (entries 6-9 in Table 1) possess larger charges than do the plenary ions. Hence, despite the clear discontinuity in particle sizes obtained using the plenary versus defect structures (Fig. 3), the larger charges of the latter anions might arguably play a critical role in arresting crystal growth.

To assess this, $\left[\alpha-\mathrm{AlW}_{11} \mathrm{O}_{39}\right]^{9-}$ was reacted with $\mathrm{Ni}(\mathrm{II})$, giving $\left[\alpha-\mathrm{AlNi}^{\mathrm{II}} \mathrm{W}_{11} \mathrm{O}_{39}\right]^{7-}$, in which $\mathrm{Ni}(\mathrm{II})$ is bound inside the defect site $^{10}$ (see ESI $\dagger$ ). The Ni(II) complex possesses the same negative charge as $\mathbf{1}$, but now lacks the binding site common to the lacunary anions. When $\mathrm{Cl}^{-}$was reacted with $\mathrm{Ag}^{+}$in the presence of $\left[\alpha-\mathrm{AlNi}^{\mathrm{II}} \mathrm{W}_{11} \mathrm{O}_{39}\right]^{7-}$, the result was effectively the same as that obtained for the plenary ions (open diamond in Fig. 3). This demonstrates that arrested growth and stabilization of the $\mathrm{AgCl}$ nanocrystals is a result of cluster-anion structure, rather than of charge alone, and assigns a controlling role to the defect (binding) site of the lacunary anions.

To investigate this further, $\mathrm{Ag}^{+}$was reacted with $\left[\alpha-\mathrm{PW}_{11} \mathrm{O}_{39}\right]^{7-}(\mathbf{1})$ in water and the resultant colorless crystals were analyzed by single-crystal X-ray crystallography. $\ddagger$ In the solid-state structure $\mathrm{K}_{6}\left[\alpha-\mathrm{AgPW}_{11} \mathrm{O}_{39}\right] \cdot 12 \mathrm{H}_{2} \mathrm{O}\left(\mathrm{K}_{6} \mathbf{2} \cdot 12 \mathrm{H}_{2} \mathrm{O}\right)$, $\mathrm{Ag}^{+}$ions are bound in an "out-of-pocket" fashion to the tetradentate defect site of the mono-vacant anion (Fig. 4). $t \S^{11}$

The ionic radius of $\operatorname{Ag}(\mathrm{I})$ (drawn to scale in Fig. 4) is $1.29 \AA$-versus $0.74 \AA$ for $\mathrm{W}(\mathrm{vI})$ - and much too large for entry of $\mathrm{Ag}(\mathrm{I})$ into the potentially pentadentate binding pocket of $\mathbf{1}$. Rather, the $\mathrm{Ag}(\mathrm{I})$ ion is located $0.11 \AA$ above the $\mathrm{O}_{4}$ plane. ${ }^{7,8}$

When $\mathrm{K}_{6} \mathbf{2} \cdot 12 \mathrm{H}_{2} \mathrm{O}$ was dissolved in water $(2 \mathrm{mM})$ and one equiv. of $\mathrm{Cl}^{-}$was added, a clear solution was obtained. The $R_{\mathrm{h}}(20 \mathrm{~nm})$ and size distribution were identical to those obtained when 1 was reacted sequentially with $\mathrm{Ag}^{+}$and $\mathrm{Cl}^{-}$ (entry 6 in Table 1). This result along with the X-ray structure of $\mathrm{K}_{6} \mathbf{2} \cdot 12 \mathrm{H}_{2} \mathrm{O}$ and the data in Fig. 3 are all consistent with an "out-of-pocket" association between $\mathrm{Ag}^{+}$and $\mathbf{1}$ in solution playing a controlling role in $\mathrm{AgCl}$ nanocrystal formation. This was further assessed by UV-visible spectroscopy.

Quantitative subtraction of the UV-visible spectrum of aqueous $\mathrm{K}_{7} 1$ from that of dissolved $\mathrm{K}_{6} 2 \cdot 12 \mathrm{H}_{2} \mathrm{O}$ revealed a definitive band at $275 \mathrm{~nm}$ (see ESI $\dagger$ ). This band arises from a subtle effect of $\mathrm{Ag}^{+}$association on the shape of the broad, ligand-to-metal charge-transfer band typical of polyoxotungstates. Notably, a similar band was observed after adding 1 equiv. of $\mathrm{Ag}^{+}$to solutions of $\left[\alpha-\mathrm{SiW}_{11} \mathrm{O}_{39}\right]^{8-}$ and $\left[\alpha-\mathrm{AlW}_{11} \mathrm{O}_{39}\right]^{9-}$, but was

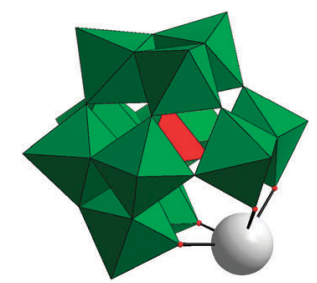

Fig. 4 Binding of $\mathrm{Ag}(\mathrm{I})$ to $\left[\alpha-\mathrm{PW}_{11} \mathrm{O}_{39}\right]^{7-}(\mathbf{1})$ in $\mathrm{K}_{6}\left[\alpha-\mathrm{AgPW}_{11} \mathrm{O}_{39}\right] \cdot 12 \mathrm{H}_{2} \mathrm{O}$. $\mathrm{The} \mathrm{Ag}(\mathrm{I})$ ion (grey) is coordinated to four terminal oxygen atoms that define the defect site of $\mathbf{1}$, with $\mathrm{Ag}-\mathrm{O}$ bond distances of 2.40(1)-2.44(1) A. Shortest distances from $\mathrm{Ag}$ to closest $\mu-\mathrm{O}$ atoms of neighboring cluster anions are: 2.74(1), 2.82(1), 3.06(2), and one shorter distance of 2.54(1). 

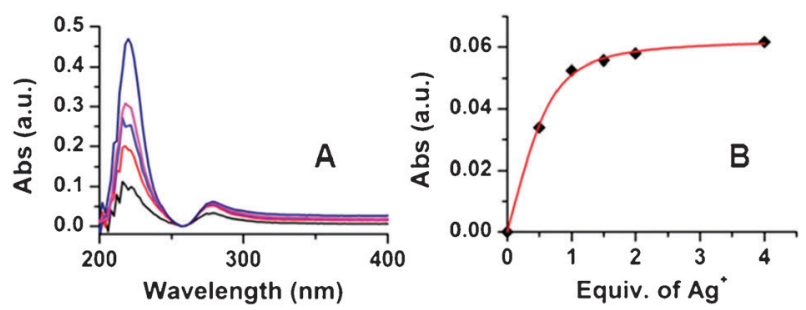

Fig. 5 Coordination of $\left[\alpha-\mathrm{PW}_{11} \mathrm{O}_{39}\right]^{7-}$ (1) to $\mathrm{Ag}^{+}$in water. (A) Increase in absorbance at $275 \mathrm{~nm}$ when $\mathrm{Ag}^{+}(0$ to $144 \mu \mathrm{M})$ is added to $36 \mu \mathrm{M}$ of 1 ; each difference spectrum was obtained by subtracting the spectrum of $\mathrm{K}_{7} \mathbf{1}$. (B) Absorbance at $275 \mathrm{~nm}$ (from panel A), as a function of equivalents of $\mathrm{Ag}^{+}$.

absent when $\mathrm{Ag}^{+}$was added to $\left[\mathrm{H}_{2} \mathrm{~W}_{12} \mathrm{O}_{40}\right]^{6-}$, which lacks a defect site for binding to $\mathrm{Ag}^{+}$.

The absorbance at $275 \mathrm{~nm}$ was then used to quantify association of $\mathrm{Ag}^{+}$to 1 as a function of added $\mathrm{AgNO}_{3}$ (Fig. 5A; the absorbance at $220 \mathrm{~nm}$ is due to $\mathrm{NO}_{3}{ }^{-}$). The absorbance data gave a good fit when evaluated using a massbalance equation derived for $1: 1$ association of $\mathrm{Ag}^{+}$to $\mathbf{1}$, consistent with specific binding to the terminal oxide ligands at the periphery of the defect site of $\mathbf{1}$ (Fig. 5B; see ESI $\dagger$ ).

Moreover, the functional dependence of absorbance on $\left[\mathrm{Ag}^{+}\right]$gave an association constant of $K=2.6 \times 10^{5} \mathrm{M}^{-1}$. This $K$ value indicates that under the conditions of the reaction shown in Fig. 1, 95\% of the $\mathrm{Ag}^{+}$ions in solution are present as association complexes with $\mathbf{1}$.

Once formed, the $\mathrm{AgCl}$ nanocrystals are stable in solution (in the dark) for over a year and, here too, $\mathbf{1}$ plays an important role. An earlier report documents the adsorption of polyoxometalate anions onto the surfaces of colloidal AgI. ${ }^{12}$ Consistent with those findings, $\mathrm{AgCl}$ nanocrystals prepared using 1 possess a zeta potential of $-71 \mathrm{mV}$, diagnostic for anionic stabilization, yet significantly more negative than the $-49 \mathrm{mV}$ observed for dilute colloidal $\mathrm{AgCl}\left(1: 1 \mathrm{Ag}^{+}: \mathrm{Cl}^{-}\right.$, with no POM present). Excess $\mathrm{Cl}^{-}$is known to stabilize colloidal $\mathrm{AgCl}$ by association with Ag atoms on the crystalline surface. ${ }^{13}$ In the present case, however, effectively no excess $\mathrm{Cl}^{-}$is present, and control experiments show that $\mathrm{NO}_{3}{ }^{-}$is not effective (see entry 1 in Table 1). Hence, the POMs are the only anions present capable of stabilizing the $\mathrm{AgCl}$ nanocrystals. Similar to $\mathrm{Cl}^{-}$, however, anionic stabilization by the mono-vacant Keggin anions may involve binding to structurally accessible $\mathrm{Ag}(\mathrm{I})$ ions on the crystal surface. Tentative evidence for POMs on the surface of the $\mathrm{AgCl}$ nanocrystals is provided by darkfield cryo-TEM images of larger $\mathrm{AgCl}$ crystals obtained in the presence of $\left[\alpha-\mathrm{PW}_{12} \mathrm{O}_{40}\right]^{3-}$ (entry 2 in Table 1), which reveal densely packed $c a$. 1-2 nm objects on the faces of properly aligned crystals (see Fig. S7D in the ESI $\dagger$ ). What is certain, however, is that the mono-vacant POMs not only control the sizes of the $\mathrm{AgCl}$ nanocrystals, but also serve as effective stabilizing anions.

In conclusion, 4 lines of evidence show that the uniformly small nanocrystals in Fig. 2 and 3 result from association of $\mathrm{Ag}^{+}$to the defect site of the cluster-anions: (1) plenary Keggin anions give larger particle sizes and distributions, (2) the use of $\left[\alpha-\mathrm{AlNi}^{\mathrm{II}} \mathrm{W}_{11} \mathrm{O}_{39}\right]^{7-}$ (prepared for this purpose) shows that anion charge is not responsible for the smaller nanocrystals obtained using the defect ions, (3) the structure of $\mathrm{K}_{6} 2 \cdot 12 \mathrm{H}_{2} \mathrm{O}$ features "out-of-pocket" coordination of $\mathrm{Ag}^{+}$to the four oxide ligands at the periphery of the defect site of $\mathbf{1}$, and (4) UV-vis data show that prior to reaction with $\mathrm{Cl}^{-}, 95 \%$ of the $\mathrm{Ag}^{+}$ions are associated with the defect site of $\mathbf{1}$. Once formed, zeta-potential measurements and control experiments (using $\mathrm{NO}_{3}{ }^{-}$) show that the POMs serve as protecting anions for the $\mathrm{AgCl}$ nanocrystals.

These data demonstrate that "out-of-pocket" coordination of relatively large cations to the tetradendate defect sites of monovacant Keggin and Wells-Dawson anions directs the self-assembly of $\mathrm{AgCl}$ nanocubes. Having established the controlling role of ligand structure, the findings provide a rational basis for using polyoxometalates ${ }^{14}$ to prepare binary-element nano-scale analogs of numerous functional solid-state materials.

IAW and LM thank the Israel Science Foundation (248/09 and $948 / 10$, respectively) for financial support.

\section{Notes and references}

$\ddagger$ Crystal data: orthorhombic, space group Pna $2_{1}, Z=4$, $\rho_{\text {calcd }}=4.38 \mathrm{~g} \mathrm{~cm}^{-3}, a=17.902(1), b=20.696(1), c=13.2410(8) \AA$, $V=4905.9(5) \AA^{3} .63509$ measured reflections, 11347 independent $\left(R_{\mathrm{int}}=0.056\right)$. Final statistics $\left(F^{2}\right)$ are $R_{1}=0.035$ and $\mathrm{w} R_{2}=0.084$ for $I>2 \sigma(I)$. CCDC 838469 .

$\S$ Despite the presence of $\mathrm{CH}_{3} \mathrm{OH}$ and excess $\mathrm{Ag}^{+}$, the space group of $\mathrm{H}_{2} \mathrm{Ag}_{0.33} \mathrm{~K}_{3.67}\left[\mathrm{AgPW}_{11} \mathrm{O}_{39}\right] \cdot 8 \mathrm{H}_{2} \mathrm{O} \cdot \mathrm{CH}_{3} \mathrm{OH}$ (3; ref. 11), is the same as that of $\mathrm{K}_{6} 2 \cdot 12 \mathrm{H}_{2} \mathrm{O}$, and the unit-cell parameters and structures of both materials are similar (including Ag-linked chains of mono-vacant $\mathrm{PW}_{11} \mathrm{O}_{39}$ units). In 3, however, $\mathrm{Ag}(\mathrm{I})$ is bound to all $4 \mu-\mathrm{O}$ sites of neighboring anions (anti-prismatic coordination), while in $\mathrm{K}_{6} \mathbf{2} \cdot 12 \mathrm{H}_{2} \mathrm{O}$, only one of those distances is $<2.7 \AA$, the sum of the crystallographic radii of 8-coordinate $\mathrm{Ag}(\mathrm{I})$ and 2-coordinate $\mathrm{O}$ (formally 2-).

1 (a) V. Sambhy, M. M. MacBride, B. R. Peterson and A. Sen, J. Am. Chem. Soc., 2006, 128, 9798; (b) J. J. Buckley, P. L. Gai, A. Lee, L. Olivi and K. Wilson, Chem. Commun., 2008, 4013.

2 W. Chen, G. McLendon, A. Marchetti, J. M. Rehm, M. I. Freedhoff and C. Myers, J. Am. Chem. Soc., 1994, 116, 1585.

3 (a) M. Zhu, P. Chen and M. Liu, ACS Nano, 2011, 5, 4529; (b) P. Wang, B. Huang, X. Qin, X. Zhang, Y. Dai, J. Wei and M. H. Whangbo, Angew. Chem., Int. Ed., 2008, 47, 7931; (c) N. Kakuta, N. Goto, H. Ohkita and T. Mizushima, J. Phys. Chem. B, 1999, 103, 5917; (d) D. Schürch, A. Currao, S. Sarkar, G. Hodes and G. Calzaferri, J. Phys. Chem. B, 2002, 106, 12764.

4 (a) Y. Wang and I. A. Weinstock, Dalton Trans., 2010, 39, 6143; (b) Y. Wang, A. Neyman, E. Arkhangelsky, V. Gitis, L. Meshi and I. A. Weinstock, J. Am. Chem. Soc., 2009, 131, 17412; (c) R. G. Finke and S. Özkar, Coord. Chem. Rev., 2004, 248, 135.

5 (a) R. N. Biboum, C. P. N. Njiki, G. Zhang, U. Kortz, P. Mialane, A. Dolbecq, I.-M. Mbomekalle, L. Nadjo and B. Keita, J. Mater. Chem., 2011, 21, 645; (b) M. Yoon, J. A. Chang, Y. Kim, J. R. Choi, K. Kim and S. J. Lee, J. Phys. Chem. B, 2001, 105, 2539.

6 N. M. Okun, T. M. Anderson and C. L. Hill, J. Am. Chem. Soc., 2003, 125, 3194.

7 M. T. Pope, in Comp. Coord. Chem. II: From Biology to Nanotechnology, ed. A. G. Wedd, Elsevier, Oxford, 2004, vol. 4, pp. $635-678$.

8 W. Huang, M. Schopfer, C. Zhang, R. C. Howell, L. Todaro, B. A. Gee, L. C. Francesconi and T. Polenova, J. Am. Chem. Soc., 2008, 130, 481.

9 A. Neyman, L. Meshi, L. Zeiri and I. A. Weinstock, J. Am. Chem. Soc., 2008, 130, 16480.

10 J. J. Cowan, A. J. Bailey, R. A. Heintz, B. T. Do, K. L. Hardcastle, C. L. Hill and I. A. Weinstock, Inorg. Chem., 2001, 40, 6666.

11 H. I. S. Nogueira, F. A. Almeida Paz, P. A. F. Teixeira and J. Klinowski, Chem. Commun., 2006, 2953.

12 E. Matijevic, K. G. Mathai and M. Kerker, J. Phys. Chem., 1963, 67, 1995.

13 D. C. Harris, Quantitative Chemical Analysis, W. H. Freeman, New York, 7th edn, 2006, p. 1008.

14 S. Mandal, D. Rautaray, A. Sanyal and M. Sastry, J. Phys. Chem. B, 2004, 108, 7126. 